Review Article

\title{
Insights into Neuroinflammation in Parkinson's Disease: From Biomarkers to Anti-Inflammatory Based Therapies
}

\author{
Natália Pessoa Rocha, Aline Silva de Miranda, and Antônio Lúcio Teixeira \\ Laboratório Interdisciplinar de Investigação Médica, Faculdade de Medicina, Universidade Federal de Minas Gerais, \\ Avenida Professor Alfredo Balena 190, Sala 281, 30130-100, Belo Horizonte, MG, Brazil
}

Correspondence should be addressed to Natália Pessoa Rocha; npessoarocha@gmail.com

Received 5 December 2014; Revised 27 January 2015; Accepted 2 February 2015

Academic Editor: Magda Santos

Copyright ( 2015 Natália Pessoa Rocha et al. This is an open access article distributed under the Creative Commons Attribution License, which permits unrestricted use, distribution, and reproduction in any medium, provided the original work is properly cited.

\begin{abstract}
Parkinson's disease (PD) is the second most common neurodegenerative disorder worldwide, being characterized by the progressive loss of dopaminergic neurons in the substantia nigra pars compacta. Among several putative factors that may contribute to PD pathogenesis, inflammatory mechanisms may play a pivotal role. The involvement of microglial activation as well as of brain and peripheral immune mediators in PD pathophysiology has been reported by clinical and experimental studies. These inflammatory biomarkers evaluated by imaging techniques and/or by biological sample analysis have become valuable tools for PD diagnosis and prognosis. Regardless of the significant increase in the number of people suffering from PD, there are still no established diseasemodifying or neuroprotective therapies for it. There is growing evidence of protective effect of anti-inflammatory drugs on PD development. Herein, we reviewed the current literature regarding the central nervous system and peripheral immune biomarkers in $\mathrm{PD}$ and advances in diagnostic and prognostic tools as well as the neuroprotective effects of anti-inflammatory therapies.
\end{abstract}

\section{Introduction}

Parkinson's disease (PD) is the second most common neurodegenerative disorder worldwide. The major pathological findings in PD are the progressive loss of dopaminergic neurons in the substantia nigra pars compacta and the presence of intraneuronal inclusions of the protein $\alpha$ synuclein (known as Lewy bodies) [1]. Neuronal death in the substantia nigra results in dopamine deficit at the striatum and, as an outcome, the clinical hallmarks of Parkinsonism: bradykinesia, rigidity, resting tremor, and postural instability. PD diagnosis, which is essentially clinical, is based on the diagnosis of Parkinsonian syndrome and the exclusion of other causes of Parkinsonism [2]. Good response to levodopa and asymmetry of motor symptoms support the diagnosis. Although PD is traditionally regarded as a movement disorder, motor symptoms may be heralded or accompanied by several nonmotor symptoms, such as hyposmia, constipation, neuropsychiatric, and sleep disorders [3].

PD was first described in 1817 [4], and despite the wellcharacterized pathological features, the cause of neuronal death in PD remains a matter of debate. Among several putative factors that may contribute to PD pathogenesis, inflammatory mechanisms may play an important role. For instance, microglial activation is associated with dopaminergic neuronal loss, which suggests that neuroinflammatory reaction may contribute to the progressive degenerative process. Moreover, it has been reported that the protein $\alpha$-synuclein has an important role in the initiation and maintenance of inflammation in PD (see Figure 1) [5].

A recent meta-analysis revealed an overall prevalence of PD of 315 per 100,000 individuals. Prevalence of PD increases steadily with age, raising from 428 per 100,000 in individuals for the age group of 60 to 69 years, to 1,903 per 100,000 individuals for the group of 80 years or older [6]. Overall worldwide incidence of PD is estimated in 36.5 per 100,000 person-years for females and 65.5 per 100,000 personyears among males [7]. Most countries are facing marked demographic changes, with progressively larger proportion of their populations entering old age. PD affects predominantly the elderly, being a disease worthy of concern, since the causes are still unknown and the treatment is palliative and merely symptomatic. Levodopa, the first breakthrough in the treatment of $\mathrm{PD}$, is still the most effective drug for 


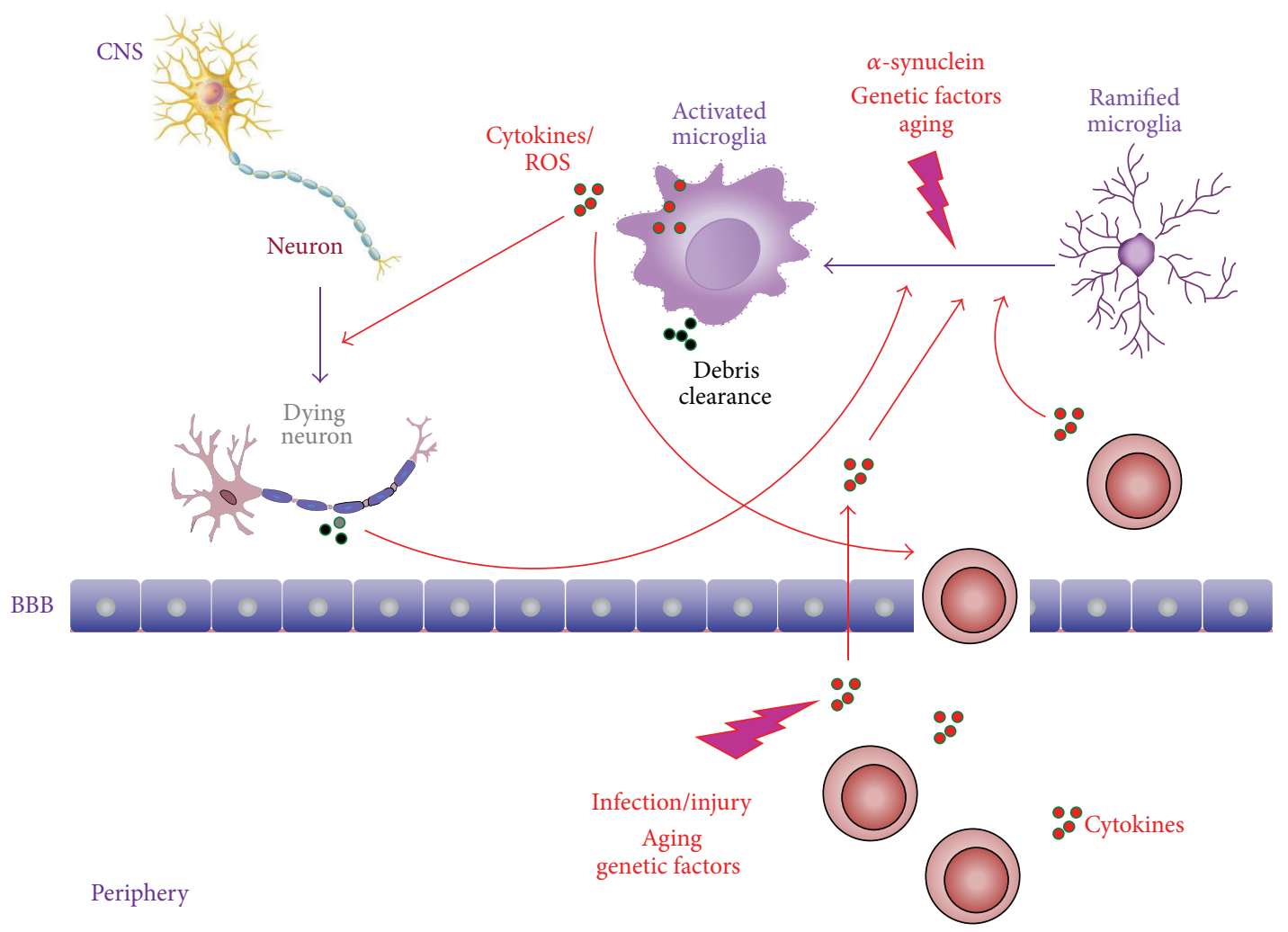

FIGURE 1: Inflammatory pathways in Parkinson's disease. An acute insult to CNS (e.g., $\alpha$-synuclein aggregates) triggers the activation of microglia with changes in their morphofunctional characteristics, increased proliferation and release of inflammatory mediators (e.g., cytokines and ROS). Inflammatory molecules can induce the recruitment of peripheral leukocytes into the CNS. This neuroinflammatory process can be regarded as beneficial for neuronal tissue since it promotes clearance of cell debris. Conversely, inflammatory mediators do not modulate only immune cells but also act on neurons, contributing to neurodegeneration. Neuronal death further activates inflammatory mechanisms, resulting in a vicious cycle of inflammation and neuronal death. Systemic inflammation due to infection or peripheral injury can exacerbate symptoms and promote neuronal damage in PD. Leukocytes secrete proinflammatory cytokines which can affect the brain by several routes, including action on endothelial cells and leakage through damaged BBB. These cytokines induce self-synthesis and the synthesis of other cytokines, which can then stimulate microglia to secrete chronically inflammatory mediators, maintaining neuroinflammation and, as a consequence, slow and progressive neuronal death. Genetic and aging factors might contribute to this process. BBB: blood-brain barrier; CNS: central nervous system; PD: Parkinson's disease, ROS: reactive oxygen species.

the motor symptoms of the disease. In certain instances, other medications such as monoamine oxidase type B inhibitors, anticholinergics, and dopamine agonists may be initiated first to prevent levodopa-related motor complications [8]. Although the number of people suffering from PD rises significantly year by year, there are no established diseasemodifying or neuroprotective therapies for PD. In this scenario, in the present review, we discuss current evidence regarding the contribution of immune dysfunction and/or inflammation in PD, advances in recent image techniques as valuable tolls for PD diagnosis and progression, and the perspectives of anti-inflammatory based therapies (data are summarized in Table 1).

\section{Neuroinflammation in PD: Lessons from Post-Mortem and Neuroimaging Studies}

2.1. Microglial Activation Role in PD. The first evidence of inflammation involvement in PD was derived from James Parkinson's report on the first clinical and pathological description of the disease in the early nineteenth century [4]. More direct evidence was provided much later in the twentieth century from systematic post-mortem analysis of the brain of PD patients [9]. Based on morphological features and immunohistochemical staining against HLA-DR, human glycoprotein of the MHC-II group expressed on the surface of immunocompetent cells, a significant increase in the number of reactive microglia was found in the substantia nigra of $\mathrm{PD}$ patients. Interestingly, reactive microglia was also found to be enhanced in the hippocampus of PD patients who also presented dementia [9].

Neuronal death in PD precedes the development of motor symptoms by many years. The mechanisms underlying the progressive neurodegeneration in PD are still elusive and the discovery of the active or main driving force is of paramount importance in the search of effective therapeutic strategies. Neuroinflammation has been proposed to actively participate in PD onset and progression. An acute insult to the central nervous system (CNS) triggers microglial activation, leading to a series of changes in microglia, notably in shape, increased 
TABLE 1: Evidence regarding the contribution of immune dysfunction and/or inflammation in Parkinson's disease.

\begin{tabular}{|c|c|c|c|}
\hline Evidence & Source & Results & Reference \\
\hline \multirow{4}{*}{ CNS inflammation } & \multirow{3}{*}{ Human brain } & $\begin{array}{l}\text { Significant increase in the number } \\
\text { of reactive microglia in the } \\
\text { substantia nigra of PD patients. }\end{array}$ & {$[9,12]$} \\
\hline & & $\begin{array}{l}\text { Coexistence of } \alpha \text {-synuclein and } \\
\text { activated microglia. }\end{array}$ & {$[15]$} \\
\hline & & $\begin{array}{l}\text { Higher expression/increased levels } \\
\text { of inflammatory mediators in PD } \\
\text { brains. }\end{array}$ & {$[13,16-18]$} \\
\hline & Human CSF samples & $\begin{array}{l}\text { Increased levels of IL- } 1 \beta \text {, IL- } 2 \text {, IL- } 4 \text {, } \\
\text { IL- } 6 \text {, TGF- } \alpha \text {, free TGF- } \beta 1 \text {, and total } \\
\text { TGF- } \beta 2 \text { in the CSF of PD patients. }\end{array}$ & {$[30-32]$} \\
\hline \multirow{3}{*}{ Peripheral inflammation } & \multirow[b]{2}{*}{ Supernatants from cell cultures } & $\begin{array}{l}\text { Increased levels of IFN- } \gamma, \text { IL- } 1 \beta \text {, } \\
\text { IL- } 2 \text {, IL-3, IL-10, MIF, TNF- } \alpha \text {, and } \\
\text { its soluble receptors sTNFR } 1 \text { and } \\
\text { sTNFR } 2 \text { in PD patients samples. }\end{array}$ & {$[48-58]$} \\
\hline & & $\begin{array}{l}\text { MCP-1, MIP- } 1 \alpha \text {, IL- } 8 \text {, IFN- } \gamma \text {, IL- } 1 \beta \text {, } \\
\text { and TNF- } \alpha \text { levels were significantly } \\
\text { higher in PD patients. }\end{array}$ & {$[65]$} \\
\hline & Blood leukocytes & $\begin{array}{l}\text { PD patients exhibited lower total } \\
\text { lymphocyte counts; decrease in the } \\
\text { percentage of T (CD3+) and B } \\
\text { (CD19+) cells and reduction in T } \\
\text { helper (Th, CD } 4+\text { ) lymphocytes; } \\
\text { higher percentage of NK cells. }\end{array}$ & {$[52,61,71-74,77]$} \\
\hline Genetic evidence & DNA extracted from brain, blood, or buccal samples & $\begin{array}{l}\text { Enhancement in IL- } 1 \beta \text { 511, IL- } 6 \text {, and } \\
\text { TNF- } \alpha \text { polymorphisms. }\end{array}$ & {$[21-24]$} \\
\hline \multirow{3}{*}{ Epidemiological evidence } & \multirow{3}{*}{ Clinical and population-based studies } & $\begin{array}{l}\text { NSAIDs use was associated with a } \\
\text { lower risk for PD. }\end{array}$ & {$[91,92,94,95,104]$} \\
\hline & & $\begin{array}{l}\text { IFN- } \alpha \text {-induced Parkinsonism in } \\
\text { chronic hepatitis [67-69]. }\end{array}$ & {$[67-69]$} \\
\hline & & $\begin{array}{l}\text { The relationship between } \mathrm{PD} \text { and } \\
\text { systemic infections (severe } \\
\text { influenza). }\end{array}$ & {$[70]$} \\
\hline
\end{tabular}

CSF: cerebrospinal fluid; CNS: central nervous system; IFN: interferon, IL: interleukin; MIF: migration inhibitory factor; MCP: monocyte chemotactic protein; MIP: macrophage inflammatory protein; NSAIDs: nonsteroidal anti-inflammatory drugs; PD: Parkinson's disease; TGF: transforming growth factor; TNF: tumor necrosis factor; sTNFR: TNF soluble receptor.

proliferation, and production of inflammatory mediators that can stimulate the recruitment of peripheral leukocytes to the CNS. This inflammatory process can be regarded as beneficial for neuronal tissue, since it promotes clearance of cell debris and secretion of neurotrophic factors. Conversely, inflammatory mediators do not only modulate immune cells but also act on neurons and contributing to neurodegeneration. Neuronal death further activates inflammatory mechanisms, resulting in a vicious cycle of inflammation and neuronal death. Therefore, inflammatory responses, although essential for tissue homeostasis, can contribute to neuronal injury when it is not controlled and/or chronic (Figure 1). As neural tissues have a restricted cell renewal and regenerative capacity, CNS is extremely vulnerable to uncontrolled immune and inflammatory processes [10]. Dopaminergic neurons from substantia nigra are particularly vulnerable to microglialmediated neurotoxicity [11].

Banati et al. demonstrated higher microglial activation in the substantia nigra of patients with $\mathrm{PD}$ as indicated by increased expression of CR3/43 and EBM11, markers for activated microglia [12]. The number of activated microglia (MHC-II, ICAM-1, and LFA-1 positive cells) in the substantia nigra and putamen of PD patients also increased in parallel with neuronal degeneration in those regions. Moreover, microglial activation persisted regardless of the presence or absence of Lewy bodies and was frequently associated with damaged neurons and neuritis [13]. The lack of reactive astrocytes in autopsies of the substantia nigra and putamen from PD patients contrasts with the response (with reactive astrocytes and microglia) typically found in other neurological disorders (e.g., seizures), supporting the hypothesis that the inflammatory process in PD is a unique phenomenon [14]. Autopsy brain tissue acquired from substantia nigra and basal ganglia of PD patients demonstrated that $\alpha$-synuclein is present in regions of brain where microglial activation is known to be also present. Furthermore, an in vitro stimulation of murine microglia with aggregated and nitrated $\alpha$ synuclein shift microglial morphology to an amoeboid shape 
and elicited dopaminergic neurotoxicity. The mechanism by which $\alpha$-synuclein activates and alters the function of microglia in PD is not yet clear, although evidence from genomic and proteomic assays has supported a role for the transcript factor nuclear factor-kappa B [15]. Taken together these studies provide evidence supporting CNS immune resident cells role in $\mathrm{PD}$. Whether microglia activation is a secondary event following the ongoing neurodegeneration or a primary inducer of the disease remains to be defined.

\subsection{Central Nervous System Inflammatory Mediators in PD.} Over the past decades, apart from microglia activation, a growing body of clinical and experimental research has been supporting a role for oxidative stress and inflammatory mediators (cytokines and chemokines), events potentially associated with microglial reaction, in PD [13, 16-18]. For instance, higher expression of the chemokine receptor CXCR4 and of its natural ligand CXCL12 was found in dopaminergic neurons of the substantia nigra of patients with $\mathrm{PD}$, and this was associated with an increase in microglial activation [18]. CXCL12/CXCR4 signaling can induce neurotoxic events, including activation of caspase-3, leading to neuronal death by apoptosis. Negative effects on the CNS mediated by CXCL12 could be induced through a direct action on dopaminergic neurons expressing CXCR4 or the release of cytokines from microglia $[18,19]$. A direct link between CXCL12/CXCR4 upregulation and loss of dopaminergic neurons was provided in an animal model of degeneration of the nigrostriatal system following 1methyl-4-phenyl-1,2,3,6-tetrahydropyridine (MPTP) administration, a well-recognized model of PD [18]. The presence of activated microglia expressing the inflammatory cytokines interleukin- (IL-) 6 and tumor necrosis factor(TNF-) $\alpha$, as well as enzymes associated with inflammation, such as inducible isoform of nitric oxide synthase (iNOS) and cyclooxygenase-2 (COX-2) was also evidenced by immunohistochemistry assays in post-mortem brain tissue from $\mathrm{PD}$ patients $[13,16,20]$. A previous study demonstrated an enhancement in the inflammatory cytokine IL-1 $\beta 511$ polymorphism from DNA extracted from brain tissues of PD patients [21]. Similar findings were reported for IL-6 and TNF- $\alpha$ using peripheral tissue samples (i.e., blood or buccal samples), indicating polymorphisms in these cytokines as risk factors of PD [22-24].

Upregulation of inflammatory mediators involved in apoptotic cell death through TNF- $\alpha$-induced signaling pathway, including caspase-1, caspase-3, and TNF receptor R1 (TNF-R1 or p55), was identified in the substantia nigra from Parkinsonian patients, indicating the occurrence of a proapoptotic environment in PD [25]. Neutralization of soluble TNF signaling in vivo with dominant-negative TNF inhibitor XENP345 (a PEGylated version of the TNF variant $\mathrm{A} 145 \mathrm{R} / \mathrm{I} 97 \mathrm{~T}$ ) abrogated in $50 \%$ the dopaminergic neuronal degeneration in an experimental model of PD induced by striatal injection of the oxidative neurotoxin 6-hydroxydopamine (6-OHDA) [17]. A more recent study demonstrated that long-lasting TNF- $\alpha$ expression induced by the injection of an adenovector expressing soluble mouse TNF- $\alpha$ (AdTNF $\alpha$ ) directly in the substantia nigra of adult rats leads to dopaminergic neuronal death, motor symptoms, and microglia activation associated with recruitment of peripheral monocytes [26]. Similar findings were reported following chronic expression of IL-1 $\beta$ induced by 60 days administration of a recombinant adenovirus expressing IL$1 \beta$ in the substantia nigra of adult rats [27]. Interestingly, alterations in mRNA expression of mediators of the immune response during $\mathrm{PD}$, including members of the complement system, colony stimulating factors, Toll family, and cytokines, seem to occur in a brain region-dependent manner. For instance, a downregulation in the mRNA expression of tumor necrosis factor related protein 7 (C1QTNF7), a member of the complement system, was found in the substantia nigra whereas an upregulation was observed in the putamen of $\mathrm{PD}$ patients at the same stage of the disease. Immunohistochemistry also reveals the expression of cytokines, including IL-6 and TNF- $\alpha$, by microglia and neurons in the PD substantia nigra and frontal cortex [28]. Active $\mathrm{NF} \kappa \mathrm{B}$ is localized in the nucleus of subpopulations of neurons and glial cells mainly in substantia nigra and less frequently in putamen and cerebral cortex [28]. Altogether, these studies suggest an involvement of inflammation, in particular related to CNS resident immune cells activation, in the degeneration of dopaminergic neurons associated with PD.

Cerebrospinal fluid (CSF) mirrors metabolic and pathological states of the CNS more directly than any other body fluid. Therefore, CSF is a good source for neuroinflammation evaluation and PD biomarker discovery since it is more accessible than brain tissue and less costly than imaging [29]. In this regard, studies have evaluated levels of inflammatory markers in the CSF of PD patients. Increased levels of IL$1 \beta$ and IL-6 were found in the CSF of PD patients [30]. Corroborating these findings, concentrations of IL-2 and IL6 were higher in ventricular CSF from PD patients in comparison with control subjects. In addition, concentrations of IL-1 $\beta$, IL-2, IL-4, and transforming growth factor- (TGF-) $\alpha$ in ventricular CSF were higher in juvenile PD patients (PD manifesting clinically bellow the age of 40 ) than those in controls [31]. Free TGF- $\beta 1$ and total TGF- $\beta 2$ levels were elevated in post-mortem ventricular CSF of patients with $\mathrm{PD}$ in comparison with age and gender-matched controls [32]. However, one study failed to find significant differences in CSF levels of the inflammatory markers C-reactive protein (CRP), IL-6, TNF- $\alpha$, eotaxin, interferon gammainduced protein 10 (IP-10), monocyte chemotactic protein 1 (MCP-1), and macrophage inflammatory protein- (MIP-) $1 \beta$ from PD patients in comparison with a reference group [33].

Using a highly sensitive Luminex assay, one study assessed a series of CSF molecules in PD, Alzheimer's disease (AD), multiple system atrophy (MSA) patients, and healthy controls: total tau, phosphorylated tau, amyloid beta peptide 1-42 [A $\beta(1-42)]$, Flt3 ligand, and fractalkine. CSF levels of Flt3 clearly differentiated PD from MSA, a disease that clinically overlaps with PD, with excellent sensitivity (99\%) and specificity (95\%). In addition, CSF fractalkine/A $\beta(1-$ 42) ratio positively correlated with $P D$ severity and $P D$ progression. Flt3 ligand and fractalkine are inflammatory markers possibly related to $\mathrm{PD}$ [29]. 
2.3. Insights from the Genetic Leucine-Rich Repeat Kinase 2 (LRRK2) Model of Neuroinflammation Associated with PD. Animal models of PD have become valuable tools to the understanding of its pathophysiology, regardless of their limitations in mimicking all features of the human disease. Neurotoxin-based animal models (6-OHDA and MPTP), referred to as pathogenic models, have largely been used to induce selective neuronal death in both in vitro and in vivo studies. Currently, genetic-based models (or etiologic models), such as those related to mutations in the Leucinerich repeat kinase 2 (LRRK2) gene, have opened new directions of investigation of molecular and cellular mechanisms underlying PD pathogenesis $[34,35]$.

Fine-mapping, gene expression, and splicing analysis from human post-mortem brain tissues have supported a role for LRRK2 gene in PD. There is convincing evidence for a common variant PD association located outside of the LRRK2 protein coding region (rs117762348) [36]. In this scenario, it has been shown that activated myeloid lineage cells, including macrophages and microglia, presented high levels of LRRK2, suggesting an involvement of this gene in the neuroinflammation associated with $\mathrm{PD}[37,38]$. An elegant study demonstrated that $\alpha$-synuclein overexpression in rats' substantia nigra induced LRRK2 expression in activated microglial cells, and this correlated with a high expression of iNOS, known to be involved in PD [39]. LRRK2 knockout rats are protected from dopaminergic neurodegeneration elicited by $\alpha$-synuclein overexpression or intracranial administration of lipopolysaccharide (LPS). Neuroprotection observed in the absence of LRRK2 was associated with reduction in proinflammatory CD68-positive myeloid cells in the substantia nigra, indicating an involvement of LRRK2 in conditions where neuroinflammation may underlie neuronal dysfunction and degeneration such as PD [39].

2.4. Positron Emission Tomography (PET) as a Diagnostic Tool for Neuroinflammation Related to PD. Positron emission tomography (PET) is a noninvasive functional imaging technique that detects gamma rays emitted by a positron-emitting radionuclide (tracer) which is introduced into the body on a biologically active molecule [40].

The isoquinoline carboxamide PK11195 is currently the most widely used ligand for the translocator protein $18 \mathrm{kDa}$ (TSPO, also known as peripheral benzodiazepine receptor). TSPO is a marker of microglial activation and has been used to assess and quantify the dynamics of activated microglia in neurodegenerative diseases, including PD. $\left[{ }^{11} \mathrm{C}\right] \mathrm{PK} 11195$ is used in PET studies for imaging brain inflammation in vivo [41]. PET studies using $\left[{ }^{11} \mathrm{C}\right] \mathrm{PK} 11195$ demonstrated increased binding potential values (parameter that mixes receptor density with ligand affinity) in the midbrain as well as in the pons, basal ganglia, and frontal and temporal cortices in PD, indicating an anatomically widespread distribution of microglial activation, possibly associated with the pathological process of PD [42, 43]. Longitudinal analysis of these patients revealed stable $\left[{ }^{11} \mathrm{C}\right] \mathrm{PK} 11195$ binding potential values, indicative of early activation of microglia in PD pathogenesis [43]. However, $\left[{ }^{11} \mathrm{C}\right]$ PK11195 tracer cannot distinguish between microglial protective or damaging profile. To overcome this, a PET tracer for the dopaminetransporter (DAT), $\left[{ }^{11} \mathrm{C}\right] \mathrm{CFT}$, has been used in conjunction with $\left[{ }^{11} \mathrm{C}\right] \mathrm{PK} 11195$ in order to further investigate microglial activation in parallel with the viability of the presynaptic dopaminergic neurons. Midbrain $\left[{ }^{11} \mathrm{C}\right] \mathrm{PK} 11195$ binding potential levels were inversely correlated with $\left[{ }^{11} \mathrm{C}\right] \mathrm{CFT}$ binding potential values in the putamen and positively correlated with the severity of motor symptoms, suggesting that neuroinflammation associated with microglial activation might contribute to the progression of the disease [44]. PET imaging has also been employed to investigate in vivo potential therapeutic strategies for PD. For instance, $\left[{ }^{11} \mathrm{C}\right]$ PK11195 PET was used to evaluate the ability of COX2 inhibition with celecoxib to reduce neuroinflammation in PD patients. Patients showed higher putamen and midbrain binding potential in comparison with controls, but considerable overlap was seen between groups, and differences were not statistically significant. This prevented reliable assessment of the changes in the $\left[{ }^{11} \mathrm{C}\right] \mathrm{PK} 11195$ uptake by celecoxib treatment [45]. In a rat model of PD induced by intrastriatal administration of 6-OHDA, PET imaging revealed that the COX-2 inhibitor celecoxib decreased microglial activation and prevented dopaminergic neuron degeneration [46]. A study conducted by Edison et al. demonstrated by PET analysis that both PD patients with or without dementia presented significant microglial activation in cortical brain regions, suggesting that neuroinflammation could be an early phenomenon in PD, persisting as the disease progress [47].

\section{Peripheral Immune Response in PD}

3.1. Peripheral Immune Biomarkers. A great body of evidence regarding peripheral inflammatory/immune markers has supported the hypothesis of inflammation involvement in PD. Studies of cytokines in serum or plasma have revealed increased levels of proinflammatory cytokines such as TNF$\alpha[48,49]$ and its soluble receptors sTNFR1 [50, 51] and sTNFR2 [51] and IL-1 $\beta$ [52] in PD patients in comparison with matched controls. Increased serum levels of macrophage migration inhibitory factor (MIF) were found in PD patients in comparison with healthy subjects [53]. Also the levels of IL-2 [54, 55], interferon (IFN)- $\gamma$ [54], IL-6 [49, 54, 56, 57], and the anti-inflammatory cytokine IL-10 were described to be increased in PD $[54,58]$. IL-6 plasma concentration was prospectively associated with an increased risk of developing PD [58]. In contrast, some authors failed to show significant alterations in cytokine levels in PD. Peripheral levels of the cytokines IL1- $\alpha$, IL-6, TNF- $\alpha$ [50, 52, 59, 60], IFN- $\gamma$, IL-2, IL-4, IL-10 [61], and IL-12 [62] were similar in PD patients and age- and gender-matched controls. Circulating levels of the chemokines MIP-1 $\alpha$, IL-8 [63], eotaxin, eotaxin-2, IP-10 $[63,64]$, and MCP-1 [64] did not differ between PD patients and controls. These controversial findings could be explained, at least in part, by methodological differences among the studies, including heterogeneous PD samples and different techniques to measure the molecules.

Apart from serum/plasma studies, the concentration of cytokines produced by peripheral cells in vitro has been 
assessed in PD. Both basal production and LPS-induced production of MCP-1, MIP- $1 \alpha$, IL- 8 , IFN- $\gamma$, IL- $1 \beta$, and TNF$\alpha$ were significantly higher in $\mathrm{PD}$ patients compared with control subjects [65]. Conversely, the secretion of IL-2 by peripheral blood mononuclear cells (PBMC) after mitogenic stimulation was decreased in $\mathrm{PD}$ patients in comparison with controls, whereas IL-6, IFN- $\alpha$, IFN- $\gamma$, and sIL-2R levels were comparable in both groups [66].

Several case reports of IFN- $\alpha$-induced Parkinsonism in chronic hepatitis patients further corroborate the hypothesis of the role played by peripheral inflammation in PD pathogenesis [67-69]. The relationship between PD and systemic infections also supports this hypothesis. For instance, in a population-based case-control study in British Columbia, Canada, severe influenza infection was associated with PD, although this effect was attenuated when cases were restricted to those occurring ten or more years before diagnosis (Figure 1) [70].

3.2. Peripheral Immune Cells. Studies have also described changes in the percentage of peripheral blood immune cells in $\mathrm{PD}$, such as lower total lymphocyte counts in comparison with controls [71-73]. Reduction in the total number of lymphocytes may result from the decrease in the percentage of $\mathrm{T}(\mathrm{CD} 3+)$ and $\mathrm{B}(\mathrm{CD} 19+)$ cells in PD patients. Changes in $\mathrm{CD} 3+$ cells were associated with a reduction in $\mathrm{T}$ helper (Th, CD4+) lymphocytes, while T cytotoxic (CD8+) cells increased or remained unchanged [71-74]. Lower number of CD4+ cells could be explained by the fact that in PD these cells presented both increased spontaneous apoptosis and activation-induced apoptosis [75].

Not only the percentage of circulating immune cells but also their activation profile must be taken into account when evaluating immune parameters. One study showed that the number of "naïve" (CD4+CD45RA+) and memory helper $(\mathrm{CD} 4+\mathrm{CD} 29+) \mathrm{T}$ cells was decreased, while the number of activated (CD4+CD25+) T cells was increased in PD [71]. In addition, impaired ability of regulatory $\mathrm{T}$ cells (Treg) to suppress effector $\mathrm{T}$ cell function has been described in PD patients [73]. Increased oxidative stress may also be associated with changes in lymphocyte profile in $\mathrm{PD}$, since both whole cell and mitochondrial reactive oxygen species (ROS) in peripheral blood mononuclear cells are increased in $\mathrm{PD}$ [76].

Some studies have reported similar percentages of CD3+ lymphocytes in PD patients and control subjects $[52,72]$. T helper lymphocytes (CD4+) were decreased, while CD8+ cell counting increased in $\mathrm{PD}$ [72].

There is evidence of higher percentage of natural killer (NK) cells in peripheral blood of PD patients compared to controls, and this increase has been associated with disease severity and progression $[52,61,77]$. Despite increased number of NK cells in PD, their activity seems to be unchanged in $\mathrm{PD}[61,77]$.

3.3. The Concomitant Effect of Inflammaging. PD is unequivocally an age-related disorder. Aging is a complex process accompanied by many physiological changes, notably in the immune system. Aging results in an increase in systemic levels of inflammatory markers, indicating the presence of subtle chronic inflammation, a phenomenon known as inflammaging. Chronic inflammation damages cells of the brain, heart, arterial walls, and other body structures, contributing to the onset and progression of a broad spectrum of degenerative diseases of aging, including heart disease, rheumatoid arthritis, AD, and PD. Inflammation generates oxidative stress, which might contribute to neuronal death in diseases such as $\mathrm{AD}, \mathrm{PD}$, and amyotrophic lateral sclerosis (ALS) (Figure 1) [78].

\section{GWAS Studies: Further Evidence for a Role of Inflammation in PD}

Genome-wide association studies (GWAS) have also identified genetic markers that link PD and inflammation. Hamza et al. detected an association between PD and the human leukocyte antigen (HLA) region (chromosome 6p21.3), finding replicated in two datasets with Caucasians (NorthAmerican of European ancestry). Associations were particularly strong for individuals with sporadic and late-onset PD and men. The variant most strongly associated with PD was rs3129882 in intron 1 of HLA-DRA [79]. The protein chains are encoded by the closely linked HLA-DRA and HLA-DRB form the class II HLA-DR antigens that are expressed by antigen-presenting cells, including microglia in the brain, and interact with T-cell receptors [79]. This result is in line with PD specific overexpression of HLA-DR antigens in substantia nigra [9]. One study has also confirmed HLA region as PD risk locus among the Dutch population [80].

One GWAS was conducted to identify common genetic variants associated with motor and cognitive outcomes in PD. The single nucleotide polymorphisms (SNP) rs10958605 (C8orf4 gene) and rs6482992 (CLRN3 gene) were associated with motor and cognitive outcomes, respectively. The encoded protein by C8orf 4 gene may play a role in the NF- $\kappa \mathrm{B}$ and ERK1/2 signaling pathways, highlighting inflammation as a possible pathogenesis mechanism for progression in $\mathrm{PD}$ [81].

A recent meta-analysis has identified four loci, including the HLA region, that contain a secondary independent risk variant for PD that exerts an effect independently of the primary risk allele [82].

Genetic factors may also be essential in determining an individual's susceptibility to inflammation-induced nigral dopaminergic neuronal cell death (Figure 1) [83].

\section{Immune Changes Induced by Antiparkinsonian Drugs}

Long-term treatment with antiparkinsonian drugs may result in changes in immune system. For example, treatment with amantadine, originally established as an antiviral drug, was associated with an increase of the CD4 : CD8 ratio [84]. Treatment with amantadine has been described to increase IL-2 levels $[85,86]$. The same was not observed in patients in use of levodopa as monotherapy [85]. Levodopa therapy induced changes in T lymphocytes proteome [87]. Levodopa-treated 
patients showed significantly higher IL-15 and RANTES circulating levels in comparison with healthy controls and higher, but not statistically significant levels, with respect to untreated patients [88].

In order to evaluate a putative immunomodulatory role of levodopa, PBMC of PD patients and controls were incubated in vitro with the drug. Levodopa caused an inhibition of mitogen-induced proliferation, stimulation of IL- 6 , and TNF- $\alpha$ production, whereas the secretion of IL- $1 \beta$ and IL- 2 was not affected in both groups [89].

\section{Nonsteroidal Anti-Inflammatory Drugs (NSAIDs) Use and Risk of PD}

Based on the hypothesis that neuroinflammation is involved in PD pathophysiology, epidemiological studies have evaluated nonsteroidal anti-inflammatory drugs (NSAIDs) use and risk of PD. The first study conducted with this purpose was a prospective cohort in which the regular use of NSAIDs, but not aspirin, was associated with a delay or prevention of PD onset [90]. The same research group later investigated whether NSAIDs use was associated with a lower risk for PD in a large cohort with more detailed information on different types of NSAIDs. They found no association between the use of aspirin, other NSAIDs, or acetaminophen and PD risk. Interestingly, $\mathrm{PD}$ risk was lower among ibuprofen users than nonusers, suggesting that ibuprofen use may delay or prevent the onset of PD [91]. In line with these results, a prospective study revealed that ibuprofen users had a significantly lower PD risk than nonusers, even when adjusting for age, smoking, caffeine consumption, and other covariates. The same effect was not observed for aspirin, other NSAIDs, or acetaminophen [92]. Since only the use of ibuprofen, but not other NSAIDs, was associated with lower PD risk, some specific effects of ibuprofen may be important. In fact, an earlier study examined the effects of NSAIDs drugs on cultured primary rat embryonic neurons from mesencephalon, the area primarily affected in PD. Ibuprofen protected both dopaminergic neurons and other neurons against glutamate toxicity. In addition, ibuprofen alone increased the relative number of dopaminergic neurons by $47 \%$ [93].

In contrast with the above mentioned studies, a population-based study described a decreased risk of PD among regular aspirin users. A stronger protective effect was observed for regular nonaspirin NSAIDs users. It is noteworthy that the aspirin effect differed by gender, showing a protective effect only in women, especially among long-term regular users [94]. The most recent study supporting the association between NSAIDs and reduced PD risk was conducted in 2008. NSAIDs use was described to significantly reduce PD risk in $20 \%$ to $30 \%$. The effect of the combination of NSAIDs use and smoking and coffee consumption was also evaluated. People who were at the highest exposure to smoking and coffee and used NSAIDs had an estimated $87 \%$ reduction in PD risk. As properly stated by the authors, whether this finding reflects true biological protection needs to be further investigated [95].
There are studies that failed to show any association between NSAIDs use and PD [96-102]. The discrepant results may be due to different methods used to conduct the investigations, especially how authors collected data about NSAID use (medical records, self-report, pharmacy databases, etc.) and the evaluated population.

Several case-control studies have been performed to examine the association between NSAIDs use and PD risk. Given the discrepancy in results, meta-analysis is of great value to better define this association. A meta-analysis with this purpose concluded that NSAIDs do not seem to modify the risk of PD. However, ibuprofen may have a mild protective effect in lowering the risk of PD [103]. Another meta-analysis estimated an overall reduction in $15 \%$ in PD incidence among users of nonaspirin NSAIDS, with a similar effect observed for ibuprofen use. The protective effect of nonaspirin NSAIDs was more pronounced among regular and long-term users. No protective effect was observed for aspirin or acetaminophen [104]. In conclusion, there is evidence for a protective effect of nonaspirin NSAIDs use in relation to $\mathrm{PD}$, which is consistent with the neuroinflammatory hypothesis for PD pathogenesis.

In this scenario, among several studies evaluating antiinflammatory strategies in animal models of $\mathrm{PD}$, one is noteworthy. The nitric oxide (NO)-NSAID HCT1026 [2fluoro- $\alpha$-methyl(1,1'-biphenyl)-4-acetic-4-(nitrooxy)butyl ester], NO-donating flurbiprofen, is an anti-inflammatory agent obtained by derivatization of conventional NSAIDs with a NO-donating moiety which strongly reduces their untoward side effects without altering the anti-inflammatory effectiveness. Oral treatment with HCT1026 showed a safe profile and a significant efficacy in counteracting MPTPinduced dopaminergic neurotoxicity, motor impairment, and microglia activation in aging mice [105], providing a promising approach towards the development of effective pharmacological neuroprotective strategies against PD.

\section{Autoimmunity and Immune-Based Therapies in PD}

PD has been associated with autoimmunity. Juvenile Parkinsonism has been reported as a manifestation of systemic lupus erythematosus [106]. Anecdotal reports tried to establish an association between PD and rheumatoid arthritis $[107,108]$. Antibodies against dopaminergic neurons were demonstrated in the serum of a patient with a complex autoimmune disorder and rapidly progressing PD [109]. One study reported significantly higher antibody levels towards monomeric $\alpha$-synuclein in the sera of PD patients compared to controls, and their levels decreased with PD progression. According to these authors, this possibly indicates a protective role of autoimmunity in maintaining body homeostasis and clearing protein species whose imbalance may lead to misfolded protein aggregation [110].

All currently available treatments for PD are of only symptomatic benefit, and a pharmacological strategy with disease-modifying effect is highly needed. In this context, immune-based therapies have been proposed for PD 
treatment. The first strategy was based on immunotherapy against aggregated forms of $\alpha$-synuclein. Transgenic mice displaying abnormal accumulation of human $\alpha$-synuclein and $\alpha$-synuclein-immunoreactive inclusion-like structures in the brain were vaccinated with human $\alpha$-synuclein. There was decreased accumulation of aggregated $\alpha$-synuclein in neuronal cell bodies and synapses, and, as a consequence, reduced neurodegeneration. Similar effects were observed with an exogenously applied FITC-tagged $\alpha$-synuclein antibody [111]. The same work group showed that passive immunization with a monoclonal $\alpha$-synuclein antibody (9E4) against the $\mathrm{C}$-terminus $\alpha$-synuclein reduced the accumulation of calpain-cleaved $\alpha$-synuclein in axons and synapses in the $\alpha$-synuclein transgenic mice. In addition, 9E4 was able to cross the blood brain barrier into the CNS, to bind to cells displaying $\alpha$-synuclein accumulation and to promote $\alpha$ synuclein clearance via the lysosomal pathway [112].

Studies on $\mathrm{AD}$ have provided valuable information about immunotherapy in neurodegenerative disorders. Immunotherapy against the $\beta$-amyloid peptide in $\mathrm{AD}$ showed that approaches targeting cerebral proteins can be applied to humans with relative safety. Neuropathological examination showed the clearance of amyloid plaques in brains of AN1792-vaccinated AD patients. Nonetheless, relevant issues must be considered. For instance, $\mathrm{T}$ cell responses specific for cerebral antigens need to be avoided. Another important issue is to define which patient should be vaccinated. Disease-modifying approaches are more effective when applied in the early stage of the disease, when diagnosis is not established yet [113].

AFFITOPE PD01, the most promising vaccine developed for PD so far, entered clinical trials and therefore represents the first PD vaccine to be tested clinically. AFFITOPE PD01 has been developed to induce antibodies recognizing $\alpha$ synuclein but sparing the family member $\beta$-synuclein, which has neuroprotective properties [113].

Immune stimulation in the periphery may also provide a new strategy to halt PD progression. In addition to studies on immunotherapy against aggregated forms of $\alpha$-synuclein, one study described the neuroprotective effects of Bacillus Calmette-Guérin (BCG) vaccination in the MPTP mouse model of PD. BCG vaccination had a significant beneficial effect on both striatal dopamine content and DAT ligand binding levels. BCG vaccination prevented the increase in the number of activated microglia in the substantia nigra induced by the MPTP, suggesting that general immune stimulation in the periphery can limit CNS microglia response to a neuronal insult [114].

\section{Conclusion}

We reviewed the evidence regarding the contribution of immune dysfunction and/or inflammation in PD, including microglial activation and brain and peripheral levels of immune mediators. Assessment of these biomarkers may contribute to the development of diagnostic and prognostic tools in PD. In addition, the protective role of NSAIDs further supports the neuroinflammation hypothesis in PD.

\section{Conflict of Interests}

The authors declare that there is no conflict of interests regarding the publication of this paper.

\section{Authors' Contribution}

Natália Pessoa Rocha and Aline Silva de Miranda contributed equally to the study.

\section{Acknowledgments}

This research was supported by FAPEMIG, CNPq, and CAPES.

\section{References}

[1] A. Samii, J. G. Nutt, and B. R. Ransom, "Parkinson's disease," The Lancet, vol. 363, no. 9423, pp. 1783-1793, 2004.

[2] A. J. Hughes, S. E. Daniel, L. Kilford, and A. J. Lees, "Accuracy of clinical diagnosis of idiopathic Parkinson's disease: a clinicopathological study of 100 cases," Journal of Neurology Neurosurgery and Psychiatry, vol. 55, no. 3, pp. 181-184, 1992.

[3] M. B. Stern, A. Lang, and W. Poewe, "Toward a redefinition of Parkinson's disease," Movement Disorders, vol. 27, no. 1, pp. 5460, 2012.

[4] J. Parkinson, "An essay on the shaking palsy," The Journal of Neuropsychiatry and Clinical Neurosciences, vol. 14, no. 2, pp. 223-236, 2002.

[5] K. A. Jellinger, "Neuropathology of sporadic Parkinson's disease: evaluation and changes of concepts," Movement Disorders, vol. 27, no. 1, pp. 8-30, 2012.

[6] T. Pringsheim, N. Jette, A. Frolkis, and T. D. L. Steeves, “The prevalence of Parkinson's disease: a systematic review and metaanalysis," Movement Disorders, vol. 29, no. 13, pp. 1583-1590, 2014.

[7] T. Pringsheim, K. Fiest, and N. Jette, "The international incidence and prevalence of neurologic conditions: how common are they?" Neurology, vol. 83, no. 18, pp. 1661-1664, 2014.

[8] B. S. Connolly and A. E. Lang, "Pharmacological treatment of Parkinson disease: a review," Journal of the American Medical Association, vol. 311, no. 16, pp. 1670-1683, 2014.

[9] P. L. McGeer, S. Itagaki, B. E. Boyes, and E. G. McGeer, "Reactive microglia are positive for HLA-DR in the substantia nigra of Parkinson's and Alzheimer's disease brains," Neurology, vol. 38, no. 8, pp. 1285-1291, 1988.

[10] H.-M. Gao and J.-S. Hong, "Why neurodegenerative diseases are progressive: uncontrolled inflammation drives disease progression," Trends in Immunology, vol. 29, no. 8, pp. 357-365, 2008.

[11] L. M. Collins, A. Toulouse, T. J. Connor, and Y. M. Nolan, "Contributions of central and systemic inflammation to the pathophysiology of Parkinson's disease," Neuropharmacology, vol. 62, no. 7, pp. 2154-2168, 2012.

[12] R. B. Banati, S. E. Daniel, and S. B. Blunt, "Glial pathology but absence of apoptotic nigral neurons in long-standing Parkinson's disease," Movement Disorders, vol. 13, no. 2, pp. 221227, 1998.

[13] K. Imamura, N. Hishikawa, M. Sawada, T. Nagatsu, M. Yoshida, and Y. Hashizume, "Distribution of major histocompatibility 
complex class II-positive microglia and cytokine profile of Parkinson's disease brains," Acta Neuropathologica, vol. 106, no. 6, pp. 518-526, 2003.

[14] B. Mirza, H. Hadberg, P. Thomsen, and T. Moos, "The absence of reactive astrocytosis is indicative of a unique inflammatory process in Parkinson's disease," Neuroscience, vol. 95, no. 2, pp. 425-432, 1999.

[15] A. D. Reynolds, J. G. Glanzer, I. Kadiu et al., "Nitrated alphasynuclein-activated microglial profiling for Parkinson's disease," Journal of Neurochemistry, vol. 104, no. 6, pp. 1504-1525, 2008.

[16] C. Knott, G. Stern, and G. P. Wilkin, "Inflammatory regulators in Parkinson's disease: iNOS, lipocortin-1, and cyclooxygenases-1 and -2," Molecular and Cellular Neuroscience, vol. 16, no. 6, pp. 724-739, 2000.

[17] M. K. McCoy, T. N. Martinez, K. A. Ruhn et al., "Blocking soluble tumor necrosis factor signaling with dominant-negative tumor necrosis factor inhibitor attenuates loss of dopaminergic neurons in models of Parkinson's disease," Journal of Neuroscience, vol. 26, no. 37, pp. 9365-9375, 2006.

[18] M. Shimoji, F. Pagan, E. B. Healton, and I. Mocchetti, "CXCR4 and CXCL12 expression is increased in the nigro-striatal system of Parkinson's disease," Neurotoxicity Research, vol. 16, no. 3, pp. 318-328, 2009.

[19] A. Bachis, S. A. Aden, R. L. Nosheny, P. M. Andrews, and I. Mocchetti, "Axonal transport of human immunodeficiency virus type 1 envelope protein glycoprotein 120 is found in association with neuronal apoptosis," Journal of Neuroscience, vol. 26, no. 25, pp. 6771-6780, 2006.

[20] S. Hunot, F. Boissière, B. Faucheux et al., "Nitric oxide synthase and neuronal vulnerability in Parkinson's disease," Neuroscience, vol. 72, no. 2, pp. 355-363, 1996.

[21] P. L. McGeer, K. Yasojima, and E. G. McGeer, "Association of interleukin- $1 \beta$ polymorphisms with idiopathic Parkinson's disease," Neuroscience Letters, vol. 326, no. 1, pp. 67-69, 2002.

[22] R. Krüger, C. Hardt, F. Tschentscher et al., "Genetic analysis of immunomodulating factors in sporadic Parkinson's disease," Journal of Neural Transmission, vol. 107, no. 5, pp. 553-562, 2000.

[23] A. Håkansson, L. Westberg, S. Nilsson et al., "Interaction of polymorphisms in the genes encoding interleukin- 6 and estrogen receptor beta on the susceptibility to Parkinson's disease," The American Journal of Medical Genetics Part B: Neuropsychiatric Genetics, vol. 133, no. 1, pp. 88-92, 2005.

[24] A. D. Wahner, J. S. Sinsheimer, J. M. Bronstein, and B. Ritz, "Inflammatory cytokine gene polymorphisms and increased risk of Parkinson disease," Archives of Neurology, vol. 64, no. 6, pp. 836-840, 2007.

[25] M. Mogi, A. Togari, T. Kondo et al., "Caspase activities and tumor necrosis factor receptor R1 (p55) level are elevated in the substantia nigra from Parkinsonian brain," Journal of Neural Transmission, vol. 107, no. 3, pp. 335-341, 2000.

[26] A. L. D. L. Ezcurra, M. Chertoff, C. Ferrari, M. Graciarena, and F. Pitossi, "Chronic expression of low levels of tumor necrosis factor- $\alpha$ in the substantia nigra elicits progressive neurodegeneration, delayed motor symptoms and microglia/macrophage activation," Neurobiology of Disease, vol. 37, no. 3, pp. 630-640, 2010.

[27] C. C. Ferrari, M. C. Pott Godoy, R. Tarelli, M. Chertoff, A. M. Depino, and F. J. Pitossi, "Progressive neurodegeneration and motor disabilities induced by chronic expression of IL- $1 \beta$ in the substantia nigra," Neurobiology of Disease, vol. 24, no. 1, pp. 183193, 2006.
[28] P. Garcia-Esparcia, F. Llorens, M. Carmona, and I. Ferrer, "Complex deregulation and expression of cytokines and mediators of the immune response in parkinson's disease brain is region dependent," Brain Pathology, vol. 24, no. 6, pp. 584-598, 2014.

[29] M. Shi, J. Bradner, A. M. Hancock et al., "Cerebrospinal fluid biomarkers for Parkinson disease diagnosis and progression," Annals of Neurology, vol. 69, no. 3, pp. 570-580, 2011.

[30] D. Blum-Degena, T. Müller, W. Kuhn, M. Gerlach, H. Przuntek, and P. Riederer, "Interleukin- $1 \beta$ and interleukin- 6 are elevated in the cerebrospinal fluid of Alzheimer's and de novo Parkinson's disease patients," Neuroscience Letters, vol. 202, no. 1-2, pp. 17-20, 1995.

[31] M. Mogi, M. Harada, H. Narabayashi, H. Inagaki, M. Minami, and T. Nagatsu, "Interleukin (IL)- $1 \beta$, IL-2, IL-4, IL-6 and transforming growth factor- $\alpha$ levels are elevated in ventricular cerebrospinal fluid in juvenile parkinsonism and Parkinson's disease," Neuroscience Letters, vol. 211, no. 1, pp. 13-16, 1996.

[32] M. P. Vawter, O. Dillon-Carter, W. W. Tourtellotte, P. Carvey, and W. J. Freed, "TGF $\beta 1$ and TGF $\beta 2$ concentrations are elevated in Parkinson's disease in ventricular cerebrospinal fluid," Experimental Neurology, vol. 142, no. 2, pp. 313-322, 1996.

[33] D. Lindqvist, S. Hall, Y. Surova et al., "Cerebrospinal fluid inflammatory markers in Parkinson's disease-associations with depression, fatigue, and cognitive impairment," Brain, Behavior, and Immunity, vol. 33, pp. 183-189, 2013.

[34] E. Bezard, Z. Yue, D. Kirik, and M. G. Spillantini, "Animal models of Parkinson's disease: limits and relevance to neuroprotection studies," Movement Disorders, vol. 28, no. 1, pp. 61-70, 2013.

[35] F. M. Ribeiro, E. R. D. S. Camargos, L. C. de Souza, and A. L. Teixeira, "Animal models of neurodegenerative diseases," Revista Brasileira de Psiquiatria, vol. 35, supplement 2, pp. S82S91, 2013

[36] D. Trabzuni, M. Ryten, W. Emmett et al., "Fine-mapping, gene expression and splicing analysis of the disease associated LRRK2 locus," PLoS ONE, vol. 8, no. 8, Article ID e70724, 2013.

[37] J. Thévenet, R. Gobert, R. H. van Huijsduijnen, C. Wiessner, and Y. J. Sagot, "Regulation of LRRK2 expression points to a functional role in human monocyte maturation," PLOS ONE, vol. 6, no. 6, Article ID e21519, 2011.

[38] M. S. Moehle, P. J. Webber, T. Tse et al., "LRRK2 inhibition attenuates microglial inflammatory responses," The Journal of Neuroscience, vol. 32, no. 5, pp. 1602-1611, 2012.

[39] J. P. Daher, L. A. Volpicelli-Daley, J. P. Blackburn, M. S. Moehle, and A. B. West, "Abrogation of $\alpha$-synuclein-mediated dopaminergic neurodegeneration in LRRK2-deficient rats," Proceedings of the National Academy of Sciences of the United States of America, vol. 111, no. 25, pp. 9289-9294, 2014.

[40] R. B. Banati, J. Newcombe, R. N. Gunn et al., "The peripheral benzodiazepine binding site in the brain in multiple sclerosis: quantitative in vivo imaging of microglia as a measure of disease activity," Brain, vol. 123, no. 11, pp. 2321-2337, 2000.

[41] F. Dollé, C. Luus, A. Reynolds, and M. Kassiou, "Radiolabelled molecules for imaging the translocator protein $(18 \mathrm{kDa})$ using positron emission tomography," Current Medicinal Chemistry, vol. 16, no. 22, pp. 2899-2923, 2009.

[42] Y. Ouchi, E. Yoshikawa, Y. Sekine et al., "Microglial activation and dopamine terminal loss in early Parkinson's disease," Annals of Neurology, vol. 57, no. 2, pp. 168-175, 2005.

[43] A. Gerhard, N. Pavese, G. Hotton et al., "In vivo imaging of microglial activation with $\left[{ }^{11} \mathrm{C}\right](\mathrm{R})-\mathrm{PK} 11195$ PET in idiopathic 
Parkinson's disease," Neurobiology of Disease, vol. 21, no. 2, pp. 404-412, 2006.

[44] Y. Ouchi, S. Yagi, M. Yokokura, and M. Sakamoto, "Neuroinflammation in the living brain of Parkinson's disease," Parkinsonism and Related Disorders, vol. 15, supplement 3, pp. S200-S204, 2009.

[45] A. L. Bartels, A. T. M. Willemsen, J. Doorduin, E. F. J. de Vries, R. A. Dierckx, and K. L. Leenders, " $\left[{ }^{11}\right.$ C]-PK11195 PET: quantification of neuroinflammation and a monitor of antiinflammatory treatment in Parkinson's disease?" Parkinsonism and Related Disorders, vol. 16, no. 1, pp. 57-59, 2010.

[46] R. Sánchez-Pernaute, A. Ferree, O. Cooper, M. Yu, A.-L. Brownell, and O. Isacson, "Selective COX-2 inhibition prevents progressive dopamine neuron degeneration in a rat model of Parkinson's disease," Journal of Neuroinflammation, vol. 1, article 6, 2004.

[47] P. Edison, I. Ahmed, Z. Fan et al., "Microglia, amyloid, and glucose metabolism in Parkinson's disease with and without dementia," Neuropsychopharmacology, vol. 38, no. 6, pp. 938949, 2013.

[48] D. Koziorowski, R. Tomasiuk, S. Szlufik, and A. Friedman, "Inflammatory cytokines and NT-proCNP in Parkinson's disease patients," Cytokine, vol. 60, no. 3, pp. 762-766, 2012.

[49] R. J. Dobbs, A. Charlett, A. G. Purkiss, S. M. Dobbs, C. Weller, and D. W. Peterson, "Association of circulating TNF- $\alpha$ and IL-6 with ageing and parkinsonism," Acta Neurologica Scandinavica, vol. 100, no. 1, pp. 34-41, 1999.

[50] P. Scalzo, A. Kümmer, F. Cardoso, and A. L. Teixeira, "Increased serum levels of soluble tumor necrosis factor- $\alpha$ receptor-1 in patients with Parkinson's disease," Journal of Neuroimmunology, vol. 216, no. 1-2, pp. 122-125, 2009.

[51] N. P. Rocha, A. L. Teixeira, P. L. Scalzo et al., "Plasma levels of soluble tumor necrosis factor receptors are associated with cognitive performance in Parkinson's disease," Movement Disorders, vol. 29, no. 4, pp. 527-531, 2014.

[52] Z. Katsarou, S. Bostantjopoulou, O. Hatzizisi, E. Giza, A. SolerCardona, and G. Kyriazis, "Immune factors or depression? Fatigue correlates in Parkinson's disease," Revista de Neurologia, vol. 45, no. 12, pp. 725-728, 2007.

[53] A. Nicoletti, P. Fagone, G. Donzuso et al., "Parkinson's disease is associated with increased serum levels of macrophage migration inhibitory factor," Cytokine, vol. 55, no. 2, pp. 165-167, 2011.

[54] B. Brodacki, J. Staszewski, B. Toczyłowska et al., "Serum interleukin (IL-2, IL-10, IL-6, IL-4), TNF $\alpha$, and INF $\gamma$ concentrations are elevated in patients with atypical and idiopathic parkinsonism," Neuroscience Letters, vol. 441, no. 2, pp. 158-162, 2008.

[55] G. Stypuła, J. Kunert-Radek, H. Stępień, K. Zylińska, and M. Pawlikowski, "Evaluation of interleukins, ACTH, cortisol and prolactin concentrations in the blood of patients with Parkinson's disease," NeuroImmunoModulation, vol. 3, no. 2-3, pp. 131-134, 1996.

[56] D. Lindqvist, E. Kaufman, L. Brundin, S. Hall, Y. Surova, and O. Hansson, "Non-motor symptoms in patients with Parkinson's disease-correlations with inflammatory cytokines in serum," PLoS ONE, vol. 7, no. 10, Article ID e47387, 2012.

[57] P. Scalzo, A. Kümmer, F. Cardoso, and A. L. Teixeira, "Serum levels of interleukin-6 are elevated in patients with Parkinson's disease and correlate with physical performance," Neuroscience Letters, vol. 468, no. 1, pp. 56-58, 2010.

[58] H. Chen, E. J. O’Reilly, M. A. Schwarzschild, and A. Ascherio, "Peripheral inflammatory biomarkers and risk of Parkinson's disease," American Journal of Epidemiology, vol. 167, no. 1, pp. 90-95, 2008.

[59] K. W. Hofmann, A. F. S. Schuh, J. Saute et al., "Interleukin-6 serum levels in patients with parkinson's disease," Neurochemical Research, vol. 34, no. 8, pp. 1401-1404, 2009.

[60] M. Dufek, M. Hamanová, J. Lokaj et al., "Serum inflammatory biomarkers in Parkinson's disease," Parkinsonism and Related Disorders, vol. 15, no. 4, pp. 318-320, 2009.

[61] T. Mihara, M. Nakashima, A. Kuroiwa et al., "Natural killer cells of Parkinson's disease patients are set up for activation: a possible role for innate immunity in the pathogenesis of this disease," Parkinsonism and Related Disorders, vol. 14, no. 1, pp. 46-51, 2008.

[62] M. Rentzos, C. Nikolaou, E. Andreadou et al., "Circulating interleukin-10 and interleukin-12 in Parkinson's disease," Acta Neurologica Scandinavica, vol. 119, no. 5, pp. 332-337, 2009.

[63] P. Scalzo, A. S. De Miranda, D. C. Guerra Amaral, M. De Carvalho Vilela, F. Cardoso, and A. L. Teixeira, "Serum levels of chemokines in Parkinson's disease," NeuroImmunoModulation, vol. 18, no. 4, pp. 240-244, 2011.

[64] N. P. Rocha, P. L. Scalzo, I. G. Barbosa et al., "Cognitive status correlates with CXCL10/IP-10 levels in Parkinson's disease," Parkinson's Disease, vol. 2014, Article ID 903796, 7 pages, 2014.

[65] M. Reale, C. Iarlori, A. Thomas et al., "Peripheral cytokines profile in Parkinson's disease," Brain, Behavior, and Immunity, vol. 23, no. 1, pp. 55-63, 2009.

[66] H. Klüter, P. Vieregge, H. Stolze, and H. Kirchner, "Defective production of interleukin-2 in patients with idiopathic Parkinson's disease," Journal of the Neurological Sciences, vol. 133, no. 1-2, pp. 134-139, 1995.

[67] M. Malaguarnera, A. Laurino, I. di Fazio et al., "Neuropsychiatric effects and type of IFN- $\alpha$ in chronic hepatitis C," Journal of Interferon \& Cytokine Research, vol. 21, no. 5, pp. 273-278, 2001.

[68] N. Atasoy, Y. Ustundag, N. Konuk, and L. Atik, "Acute dystonia during pegylated interferon alpha therapy in a case with chronic hepatitis B infection," Clinical Neuropharmacology, vol. 27, no. 3, pp. 105-107, 2004.

[69] M. Kajihara, S. Montagnese, P. Khanna et al., "Parkinsonism in patients with chronic hepatitis $\mathrm{C}$ treated with interferon- $\alpha 2 \mathrm{~b}$ : a report of two cases," European Journal of Gastroenterology and Hepatology, vol. 22, no. 5, pp. 628-631, 2010.

[70] M. A. Harris, J. K. Tsui, S. A. Marion, H. Shen, and K. Teschke, "Association of Parkinson's disease with infections and occupational exposure to possible vectors," Movement Disorders, vol. 27, no. 9, pp. 1111-1117, 2012.

[71] J. Bas, M. Calopa, M. Mestre et al., "Lymphocyte populations in Parkinson's disease and in rat models of parkinsonism," Journal of Neuroimmunology, vol. 113, no. 1, pp. 146-152, 2001.

[72] Y. Baba, A. Kuroiwa, R. J. Uitti, Z. K. Wszolek, and T. Yamada, "Alterations of T-lymphocyte populations in Parkinson disease," Parkinsonism and Related Disorders, vol. 11, no. 8, pp. 493-498, 2005.

[73] J. A. H. Saunders, K. A. Estes, L. M. Kosloski et al., "CD4 ${ }^{+}$ regulatory and effector/memory $\mathrm{T}$ cell subsets profile motor dysfunction in Parkinson's disease," Journal of Neuroimmune Pharmacology, vol. 7, no. 4, pp. 927-938, 2012.

[74] C. H. Stevens, D. Rowe, M.-C. Morel-Kopp et al., "Reduced T helper and B lymphocytes in Parkinson's disease," Journal of Neuroimmunology, vol. 252, no. 1-2, pp. 95-99, 2012.

[75] M. Calopa, J. Bas, A. Callén, and M. Mestre, "Apoptosis of peripheral blood lymphocytes in Parkinson patients," Neurobiology of Disease, vol. 38, no. 1, pp. 1-7, 2010. 
[76] A. Prigione, I. U. Isaias, A. Galbussera et al., "Increased oxidative stress in lymphocytes from untreated Parkinson's disease patients," Parkinsonism and Related Disorders, vol. 15, no. 4, pp. 327-328, 2009.

[77] F. Niwa, N. Kuriyama, M. Nakagawa, and J. Imanishi, "Effects of peripheral lymphocyte subpopulations and the clinical correlation with Parkinson's disease," Geriatrics and Gerontology International, vol. 12, no. 1, pp. 102-107, 2012.

[78] P. L. McGeer and E. G. McGeer, "Inflammation and the degenerative diseases of aging," Annals of the New York Academy of Sciences, vol. 1035, pp. 104-116, 2004.

[79] T. H. Hamza, C. P. Zabetian, A. Tenesa et al., "Common genetic variation in the HLA region is associated with late-onset sporadic Parkinson's disease," Nature Genetics, vol. 42, no. 9, pp. 781-785, 2010.

[80] J. Simón-Sánchez, J. J. van Hilten, B. van de Warrenburg et al., "Genome-wide association study confirms extant PD risk loci among the Dutch," European Journal of Human Genetics, vol. 19, no. 6, pp. 655-661, 2011.

[81] S. J. Chung, S. M. Armasu, J. M. Biernacka et al., "Genomic determinants of motor and cognitive outcomes in Parkinson's disease," Parkinsonism and Related Disorders, vol. 18, no. 7, pp. 881-886, 2012.

[82] M. A. Nalls, N. Pankratz, C. M. Lill et al., "Large-scale metaanalysis of genome-wide association data identifies six new risk loci for Parkinson's disease," Nature Genetics, vol. 46, no. 9, pp. 989-993, 2014.

[83] E. K. Tan, "Genetic marker linking inflammation with sporadic Parkinson's disease," Annals of the Academy of Medicine Singapore, vol. 40, no. 2, pp. 111-112, 2011.

[84] G. G. Tribl, C. Wöber, V. Schönborn, T. Brücke, L. Deecke, and S. Panzer, "Amantadine in Parkinson's disease: lymphocyte subsets and IL-2 secreting T cell precursor frequencies," Experimental Gerontology, vol. 36, no. 10, pp. 1761-1771, 2001.

[85] H. Klüter, P. Vieregge, H. Stolze, and H. Kirchner, "Defective production of interleukin-2 in patients with idiopathic Parkinson's disease," Journal of the Neurological Sciences, vol. 133, no. 1-2, pp. 134-139, 1995.

[86] K. P. Wandinger, J. M. Hagenah, H. Klüter, M. Rothermundt, M. Peters, and P. Vieregge, "Effects of amantadine treatment on in vitro production of interleukin-2 in de-novo patients with idiopathic Parkinson's disease," Journal of Neuroimmunology, vol. 98, no. 2, pp. 214-220, 1999.

[87] T. Alberio, A. C. Pippione, C. Comi et al., "Dopaminergic therapies modulate the T-CELL proteome of patients with Parkinson's disease," IUBMB Life, vol. 64, no. 10, pp. 846-852, 2012.

[88] S. Gangemi, G. Basile, R. A. Merendino et al., "Effect of levodopa on interleukin-15 and RANTES circulating levels in patients affected by Parkinson's disease," Mediators of Inflammation, vol. 12, no. 4, pp. 251-253, 2003.

[89] H. Bessler, R. Djaldetti, H. Salman, M. Bergman, and M. Djaldetti, "IL-1 $\beta$, IL-2, IL-6 and TNF- $\alpha$ production by peripheral blood mononuclear cells from patients with Parkinson's disease," Biomedicine and Pharmacotherapy, vol. 53, no. 3, pp. 141-145, 1999.

[90] H. Chen, S. M. Zhang, M. A. Hernán et al., "Nonsteroidal antiinflammatory drugs and the risk of Parkinson disease," Archives of Neurology, vol. 60, no. 8, pp. 1059-1064, 2003.

[91] H. Chen, E. Jacobs, M. A. Schwarzschild et al., "Nonsteroidal antiinflammatory drug use and the risk for Parkinson's disease," Annals of Neurology, vol. 58, no. 6, pp. 963-967, 2005.
[92] X. Gao, H. Chen, M. A. Schwarzschild, and A. Ascherio, "Use of ibuprofen and risk of Parkinson disease," Neurology, vol. 76, no. 10, pp. 863-869, 2011.

[93] D. Casper, U. Yaparpalvi, N. Rempel, and P. Werner, "Ibuprofen protects dopaminergic neurons against glutamate toxicity in vitro," Neuroscience Letters, vol. 289, no. 3, pp. 201-204, 2000.

[94] A. D. Wahner, J. M. Bronstein, Y. M. Bordelon, and B. Ritz, "Nonsteroidal anti-inflammatory drugs may protect against Parkinson disease," Neurology, vol. 69, no. 19, pp. 1836-1842, 2007.

[95] K. M. Powers, D. M. Kay, S. A. Factor et al., "Combined effects of smoking, coffee, and NSAIDs on Parkinson's disease risk," Movement Disorders, vol. 23, no. 1, pp. 88-95, 2008.

[96] T. G. Ton, S. R. Heckbert, W. T. Longstreth Jr. et al., "Nonsteroidal anti-inflammatory drugs and risk of Parkinson's disease," Movement Disorders, vol. 21, no. 7, pp. 964-969, 2006.

[97] D. B. Hancock, E. R. Martin, J. M. Stajich et al., "Smoking, caffeine, and nonsteroidal anti-inflammatory drugs in families with Parkinson disease," Archives of Neurology, vol. 64, no. 4, pp. 576-580, 2007.

[98] M. Bornebroek, L. M. L. De Lau, M. D. M. Haag et al., "Nonsteroidal anti-inflammatory drugs and the risk of Parkinson disease," Neuroepidemiology, vol. 28, no. 4, pp. 193-196, 2007.

[99] M. Etminan, B. C. Carleton, and A. Samii, "Non-steroidal antiinflammatory drug use and the risk of Parkinson disease: a retrospective cohort study," Journal of Clinical Neuroscience, vol. 15, no. 5, pp. 576-577, 2008.

[100] J. A. Driver, G. Logroscino, L. Lu, J. M. Gaziano, and T. Kurth, "Use of non-steroidal anti-inflammatory drugs and risk of Parkinson's disease: nested case-control study," British Medical Journal, vol. 342, no. 7791, article d198, p. 270, 2011.

[101] A. D. Manthripragada, E. S. Schernhammer, J. Qiu et al., "Nonsteroidal anti-inflammatory drug use and the risk of Parkinson's disease," Neuroepidemiology, vol. 36, no. 3, pp. 155-161, 2011.

[102] C. Becker, S. S. Jick, and C. R. Meier, "NSAID use and risk of Parkinson disease: a population-based case-control study," European Journal of Neurology, vol. 18, no. 11, pp. 1336-1342, 2011.

[103] A. Samii, M. Etminan, M. O. Wiens, and S. Jafari, "NSAID use and the risk of parkinsons disease: systematic review and metaanalysis of observational studies," Drugs and Aging, vol. 26, no. 9, pp. 769-779, 2009.

[104] J. J. Gagne and M. C. Power, "Anti-inflammatory drugs and risk of Parkinson disease: a meta-analysis," Neurology, vol. 74, no. 12, pp. 995-1002, 2010.

[105] F. L’Episcopo, C. Tirolo, S. Caniglia et al., "Combining nitric oxide release with anti-inflammatory activity preserves nigrostriatal dopaminergic innervation and prevents motor impairment in a 1-methyl-4-phenyl-1,2,3,6-tetrahydropyridine model of Parkinson's disease," Journal of Neuroinflammation, vol. 7, article 83, 2010.

[106] J. M. García-Moreno and J. Chacón, “Juvenile parkinsonism as a manifestation of systemic lupus erythematosus: case report and review of the literature," Movement Disorders, vol. 17, no. 6, pp. 1329-1335, 2002.

[107] M. A. Melikoglu, I. Sezer, and C. Kacar, "Rheumatoid-like hand deformities in Parkinson disease," Journal of Clinical Rheumatology, vol. 13, no. 4, pp. 236-237, 2007.

[108] T. Kogure, T. Tatsumi, Y. Kaneko, and K. Okamoto, "Rheumatoid arthritis accompanied by Parkinson disease," Journal of Clinical Rheumatology, vol. 14, no. 3, pp. 192-193, 2008. 
[109] R. C. Kunas, A. McRae, J. Kesselring, and P. M. Villiger, "Antidopaminergic antibodies in a patient with a complex autoimmune disorder and rapidly progressing Parkinson's disease," Journal of Allergy and Clinical Immunology, vol. 96, no. 5, part 1, pp. 688-690, 1995.

[110] K. Yanamandra, M. A. Gruden, V. Casaite, R. Meskys, L. Forsgren, and L. A. Morozova-Roche, " $\alpha$-synuclein reactive antibodies as diagnostic biomarkers in blood sera of parkinson's disease patients," PLoS ONE, vol. 6, no. 4, Article ID e18513, 2011.

[111] E. Masliah, E. Rockenstein, A. Adame et al., "Effects of $\alpha$ synuclein immunization in a mouse model of Parkinson's disease," Neuron, vol. 46, no. 6, pp. 857-868, 2005.

[112] E. Masliah, E. Rockenstein, M. Mante et al., "Passive immunization reduces behavioral and neuropathological deficits in an alpha-synuclein transgenic model of Lewy body disease," PLoS ONE, vol. 6, no. 4, Article ID e19338, 2011.

[113] A. Schneeberger, M. Mandler, F. Mattner, and W. Schmidt, "Vaccination for Parkinson's disease," Parkinsonism and Related Disorders, vol. 18, supplement 1, pp. S11-S13, 2012.

[114] J. Yong, G. Lacan, H. Dang et al., "BCG vaccine-induced neuroprotection in a mouse model of Parkinson's Disease," PLoS ONE, vol. 6, no. 1, Article ID e16610, 2011. 

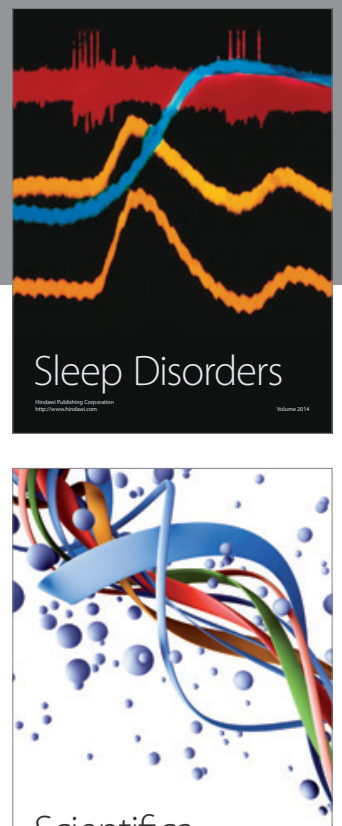

Scientifica
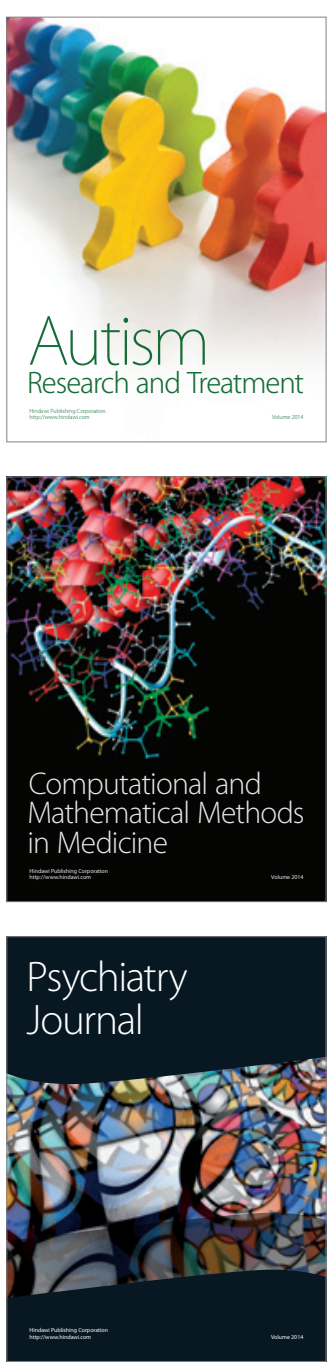
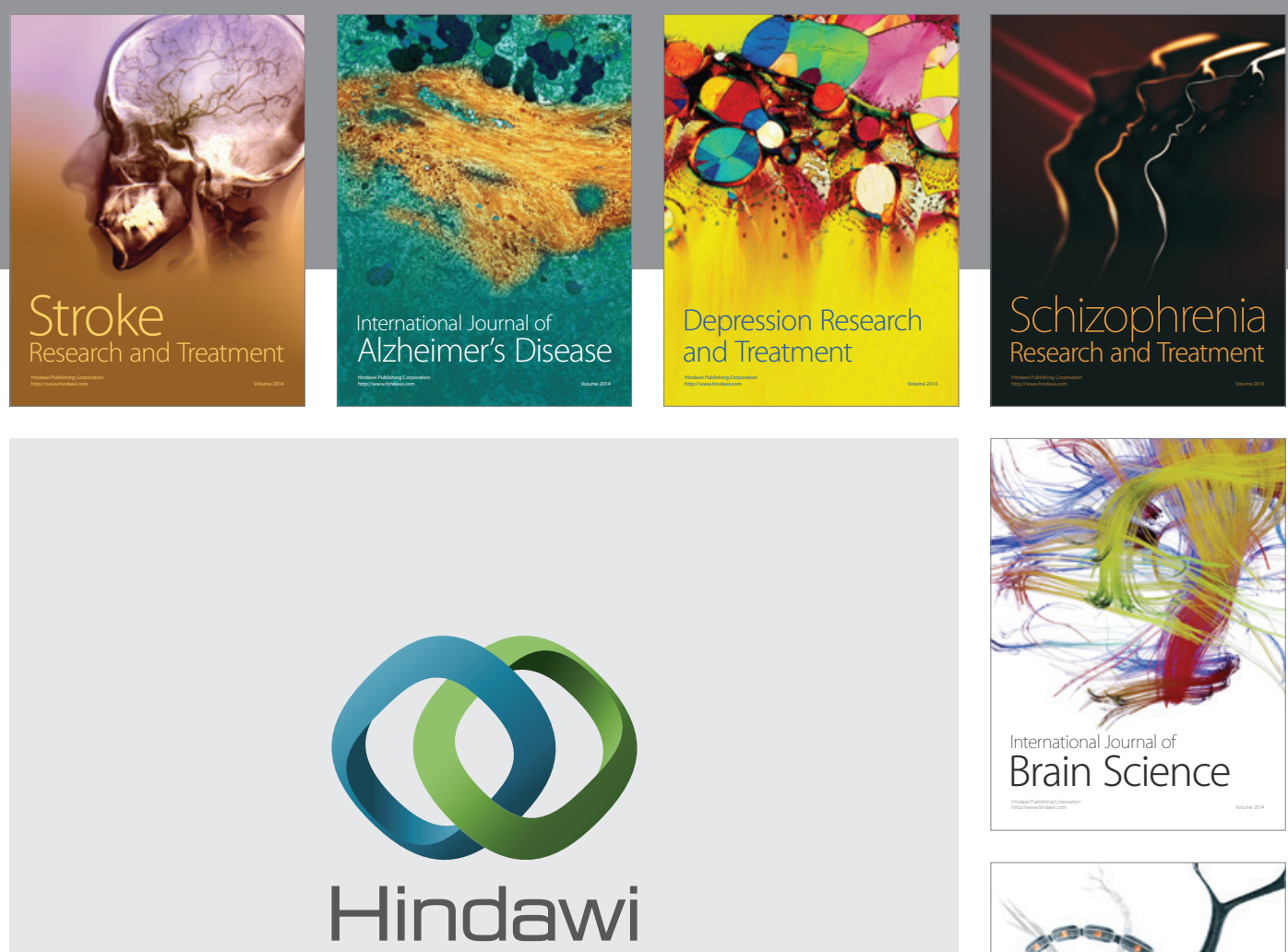

Submit your manuscripts at

http://www.hindawi.com
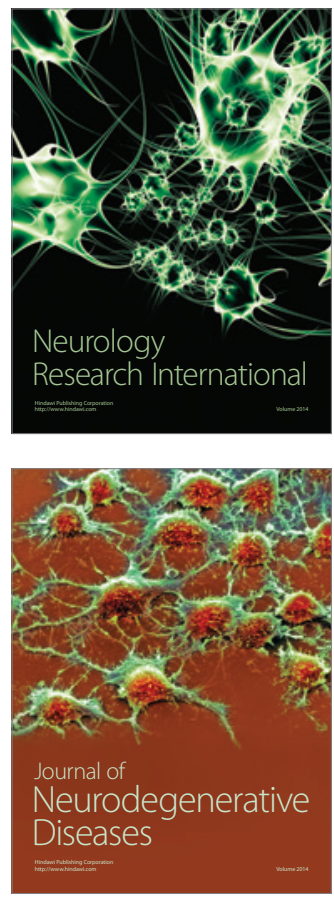

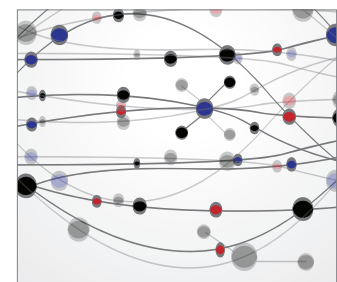

The Scientific World Journal
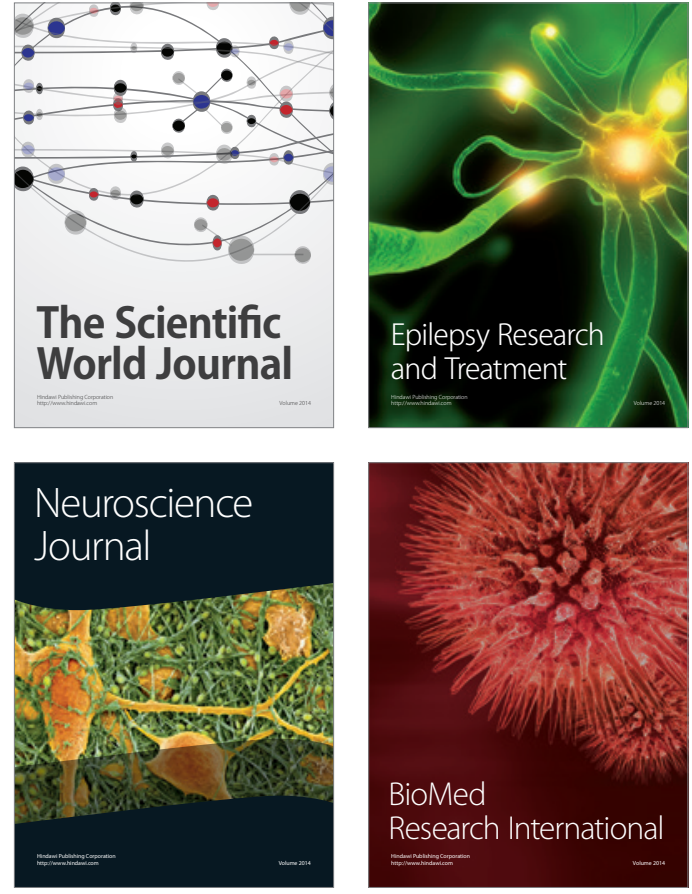

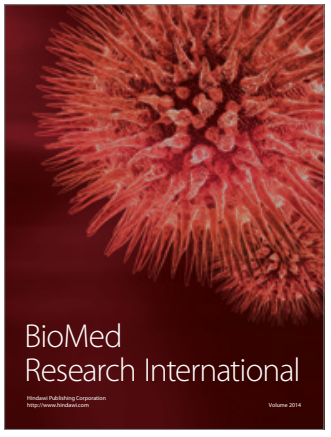

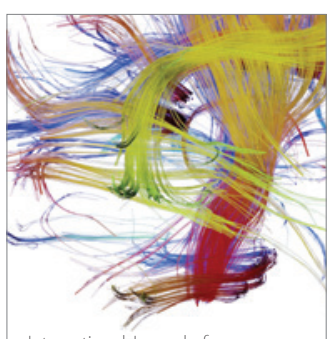

Brain Science

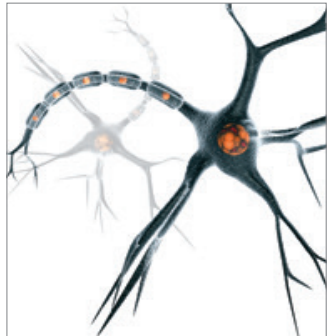

Neural Plasticity
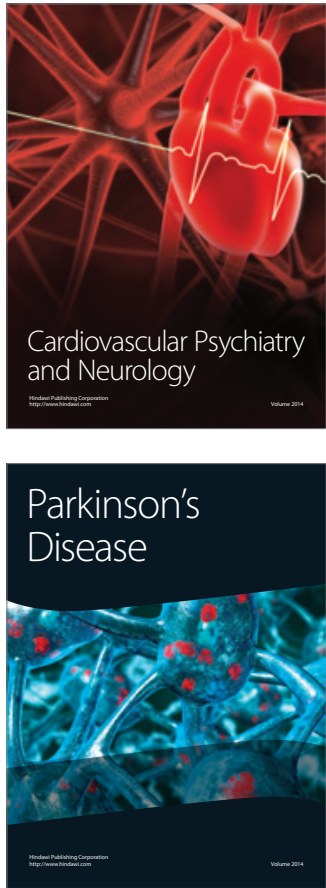